\title{
An in-Depth Analysis Identifies Two New Genetic Variants in 22q11.2 Associated with Vitiligo in the Chinese Han Population
}

\author{
Xianfa Tang \\ First Affiliated Hospital of Anhui Medical University \\ Hui Cheng \\ First Affiliated Hospital of Anhui Medical University \\ Lu Cheng \\ First Affiliated Hospital of Anhui Medical University \\ Bo Liang \\ First Affiliated Hospital of Anhui Medical University \\ Mengyun Chen \\ First Affiliated Hospital of Anhui Medical University \\ Xiaodong Zheng \\ First Affiliated Hospital of Anhui Medical University \\ Fengli Xiao ( $\nabla$ xiaofengli@126.com )
}

Institute of Dermatology and Department of Dermatology of First Affiliated Hospital, Anhui Medical University https://orcid.org/0000-0002-5048-0386

\section{Research Article}

Keywords: Vitiligo, Genetic, Association study, Susceptibility loci, SNPs

Posted Date: May 24th, 2021

DOI: https://doi.org/10.21203/rs.3.rs-491416/v1

License: (c) (i) This work is licensed under a Creative Commons Attribution 4.0 International License. Read Full License

Version of Record: A version of this preprint was published at Molecular Biology Reports on August 4th, 2021. See the published version at https://doi.org/10.1007/s11033-021-06597-2. 


\section{Abstract}

Background Vitiligo is a complex disease in which patchy depigmentation results from autoimmune loss of melanocytes in affected regions. Previously, we provided significant linkage evidence on $22 q 12$ by genomewide linkage analysis of vitiligo in the Chinese Han population. Our aim is to identify susceptibility variants associated with vitiligo at an expanded region for $22 q 12$.

Methods and Results A deep analysis of the expanded region for 22q12 locus was performed in a large GWAS dataset consisting of 1117 cases and 1701 controls by imputation. Eight nominal SNPs were selected and genotyped in an independent cohort of 2069 cases and 1370 controls of Chinese Han by using the Sequenom MassArray iPLEX1 system. Data were analyzed with PLINK 1.07 software. The C allele of rs730669 located in ZDHHC8/RTN4R was observed a strong evidence of association for vitiligo $\left(P=3.25 \times 10^{-8}, \mathrm{OR}=0.81\right)$. The $\mathrm{C}$ allele of rs4820338 located in VPREB1 and A allele of rs2051582 (a reported SNP in our previous study) located in IL2RB were suggestive evidence of association for vitligo $\left(P=1.04 \times 10^{-5}, \mathrm{OR}=0.86 ; P=1.78 \times 10^{-6}, \mathrm{OR}=1.27\right)$. The three identified SNPs showed independent associations with vitiligo by conditional logistic regression (all $P<1.0 \times 10^{-5} ;$ all $\left.D^{\prime}<0.05, r^{2}<0.0001\right)$.

Conclusions The study identifies that two novel variants rs730669 (ZDHHC8/RTN4R) and rs4820338 (VPREB1) in 22q11.2 might confer susceptibility to vitiligo and affect its disease phenotypes. The presence of multiple independent variants emphasizes an important role in the genetic pathogenesis of disease.

\section{Background}

Vitiligo is a complex disease in which patchy depigmentation results from autoimmune loss of melanocytes in affected regions. It is characterized by the loss of epidermal melanocytes leading to localized or generalized depigmentation or loss of plaque in the epidermis and mucous membranes [1]. The epidemiological surveys have shown that the incidence of vitiligo is about $0.5-1 \%$ [2]. Its underlying pathobiology may be related to the genetic, immune and environments. Linkage and association studies in multi-ethnic populations provided strong support for vitiligo susceptibility genes on chromosome (such as, 4q13-q21, 1p31, and 17p13) [3, 4]. In addition, the linkage evidence on 22q12 was found for vitiligo by our previous genomewide linkage analysis in the Chinese Han population [5]. So far, sixty genetic loci associated with disease susceptibility were identified by several genome-wide association studies (GWAS) of vitiligo in the Caucasian and Chinese $[6,7,8,9,10,11,12]$, most of which harbor genes involved in regulation of biological functions (melanocyte, apoptosis and immune). These emphasized in a common model of melanocyte autoimmune pathogenesis [13].

To find the susceptibility loci in 22q12 identified locus by linkage analysis with vitiligo [5], a fine imputation analysis was conducted by our previous GWAS dataset [11], and performed further validation analysis in an independent cohort of Chinese Han population, which provided additional information on the locus implicated in vitiligo genetic pathogenesis.

\section{Materials And Methods}

\section{Subjects}

In total, the data of our previous vitiligo GWAS from 1117 vitiligo patients and 1701 controls were used [11,12], while 2069 cases and 1370 controls were recruited for replication in this study (Table 1). All (the Chinese Han population) were collected from the multiple hospitals in China. After the written informed consent was obtained from all individuals, the blood samples, clinical and demographic information (a previous designed questionnaire) were collected from cases and controls. Based on the Declaration of Helsinki principles, this study was approved by the Institutional Ethical Committee of Anhui Medical University. According to the diagnostic criteria of the Vitiligo European Task Force [14], the clinical diagnosis of all cases were confirmed by at least two dermatologists. All controls were healthy individuals without vitiligo, family history (including first-, second- and third-degree relatives) of vitiligo, and any other autoimmune diseases or systemic disorders. Common factors (ethnicity, age and gender) were matched in case and control groups. According to the manufacturer's instructions, genomic DNA was extracted from peripheral blood lymphocytes by using QIAamp DNA Blood kit (Qiagen, Valencia, CA, USA) and was diluted to working concentrations of $20-25 \mathrm{ng} / \mathrm{ml}$ for the replication study.

\section{SNP selection for replication}

Based on our previous vitiligo GWAS [11,12] and the reference panel of 1000 Genomes Project (Mar.2012 release) [15], the imputation for a expanded region of 22q12 locus (expansion of $5 \mathrm{Mb}$ of upstream and downstream for this locus, chr 22: 20000000-42000000, hg19) was performed in 1117 vitiligo patients and 1701 controls by using Impute v2.0 [16]. The following conditions will be excluded from further analysis: 1) SNPs with low imputation confidence (INFO score $\leq 0.5), 2)$ Significant Hardy-Weinberg disequilibrium $(P<0.05), 3) \mathrm{A} M A F<1 \%, 4)$ A low call rate $<95 \%$. At last, 8 SNPs at the region showed nominal significance of association $\left(P_{\text {initial }}<0.01\right)$ in our vitiligo GWAS and were then selected for this replication study.

\section{Genotyping analysis of the replication study}

The detection primers for the 8 SNPs were designed using the MassARRAY Assay Design 3.0 software (Sequenom). Approximately 15-20 ng of genomic DNA for each sample was used to genotype. Eight SNPs were genotyped by using the Sequenom MassArray iPLEX1 system (the Key Laboratory of Dermatology, Ministry of Education, China). The DNA samples were amplified by multiplex PCR reactions, and then the PCR products were used for locus-specific singlebase extension reactions. The resulting products were desalted and transferred to a 384-element SpectroCHIP array. Allele detection was performed using MALDI-TOF MS. The mass spectrograms were analyzed by the MassARRAY Typer software (Sequenom). SNPs with MAF $<1 \%$, a call rate $<95 \%$, and deviation from Hardy-Weinberg equilibrium $(P<0.05)$ in the control subjects were excluded from further association analysis.

\section{Statistical analysis}


Association of each SNP with disease phenotype was tested in the discovery and replication samples using PLINK version 1.07 [17]. Principal component analysis was used to assess population outlier and stratification in the dataset [11]. GWAS and replication association analyses were carried out by using the Cochran-Armitagetrend test. Conditional logistic regression was used to determine whether independent effects existed and was carried out by SNPTEST (V2). The regional plot of association result was generated using LocusZoom based on the information of JPT and CHB populations from hg19/HapMap Phase II. The level of associated significance was assigned at $P$ values of less than $5.0 \times 10^{-8}$ (criterion for genome-wide significance). The sub-phenotype analyses of the associated SNPs were also performed according to the clinical features which included gender, family history, age of onset (early onset <=20 years and late onset >20 years), clinical classification (non segmental and segmental) and autoimmune disease involvement (such as, systemic lupus erythematosus, alopecia areata, thyroid disease, rheumatoid arthritis, myasthenia gravis, and scleroderma), $P$ values of less than $5.0 \times 10^{-2}$ were considered to be statistically significant.

\section{Bioinformatics analysis}

Several bioinformatics tools were utilized in this study. The HaploReg4.1 (https://pubs.broadinstitute.org/mammals/hap loreg/haploreg.php) was adopted to select the strong linked SNPs and evaluated the potential biological significance for targeted SNPs. Single Nucleotide Polymorphism database (dbSNP) was used for gene mapping (http://www.ncbi. nlm.nih.gov/snp). In addition, the expression quantitative trait loci (eQTL) studies data based on the GenotypeTissue Expression (GTEx) database, version 7 (http://www.gtexportal.org/home/) were adopted (Consortium, 2013).

\section{Results}

\section{Association between SNPs and vitiligo}

For the selected 8 SNPs, their call rates were $>95 \%$ and there were no significantly deviated from Hardy-Weinberg equilibrium $(P>0.05)$ in the control subjects for the replication study. Table 2 showed the association analysis for the 8 SNPs on $22 q 12$ for cases and controls. In replication study, the minor alleles of rs730669, rs4820338 and rs2051582 were weakly associated with vitiligo $\left(P=1.34 \times 10^{-4}, \mathrm{OR}=0.82,95 \% \mathrm{Cl}: 0.74-0.91, P=7.28 \times 10^{-3}, \mathrm{OR}=0.88,95 \% \mathrm{Cl}: 0.80\right.$ $\left.0.97, P=4.54 \times 10^{-4}, \mathrm{OR}=1.27,95 \% \mathrm{Cl}: 1.11-1.45\right)$. The combined analyses of GWAS dataset and replication stages, which showed a strong evidence of association for SNP rs730669 $\left(P=3.25 \times 10^{-8}, \mathrm{OR}=0.81,95 \% \mathrm{Cl}: 0.75-0.87\right.$, reaching genome-wide significance $)$ and suggestive evidence of association for SNPs rs $4820338\left(P=1.04 \times 10^{-5}, \mathrm{OR}=0.86,95 \% \mathrm{Cl}\right.$ : $\left.0.80-0.92\right)$ and rs $2051582\left(P=1.78 \times 10^{-6}, \mathrm{OR}=1.27,95 \% \mathrm{Cl}\right.$ : $1.15-1.40$, a reported association signal in our previous study [12]).

\section{Conditional logistic regression analysis}

To have a better understanding of the associations for the three significantly associated SNPs, we performed conditional logistic regression analysis by controlling the genetic effect of associated SNPs (Table 3). Controlling the reported SNP rs2051582, the two newly identified SNPs (rs730669 and rs4820338) also had significant associations with vitiligo $\left(P=4.15 \times 10^{-8}\right.$ and $\left.P=9.13 \times 10^{-6}\right)$. Controlling the SNP rs 730669 or rs4820338, the other two SNPs (rs 2051582 and rs4820338, rs730669 and rs2051582) also had significant associations with vitiligo $\left(P=2.17 \times 10^{-6}\right.$ and $P=5.12 \times 10^{-6}, P=7.87 \times 10^{-9}$ and $\left.P=3.07 \times 10^{-6}\right)$. Among the three SNPs, the paired SNPs were no correlated with each other in current study population (all $D^{\prime}<0.05, r^{2}<0.0001$ ).

\section{Genotype and subphenotype analysis}

The analyses of genotype-phenotype (age of onset, gender, family history, clinical classification, concomitant autoimmune diseases and Koebner phenomenon) of the three SNPs were also performed. For the SNP rs4820338, the frequency of genotype $\left(P=2.30 \times 10^{-2}\right)$ and allele $\left(P=7.78 \times 10^{-3}, \mathrm{OR}=0.87\right.$, $95 \% \mathrm{Cl}, 0.79-0.97)$ was significantly different between patients with early onset and late onset (Table 4). However, no statistical difference in different subgroups was observed for the SNPs rs730669 and rs2051582 by comparing the genotype and allele frequencies (data not shown).

\section{Functional annotation and bioinformatics analysis}

The two associated SNPs rs730669 and rs4820338 are both located at 22q11.2 (Fig 1). Rs730669 is located in 66kb downstream of Zinc finger DHHC-type containing 8 (ZDHHC8) and 27kb downstream of reticulon 4 receptor (RTN4R), rs4820338 is located in $78 \mathrm{~kb}$ upstream of $V$-set pre-B cell surrogate light chain 1 (VPREB1). The eQTL analysis showed that only SNP rs730669 was associated significantly with the expression level of $Z D H H C 8$ in cultured fibroblasts cells $\left(P=9.10 \times 10^{-6}\right)$ by using the HaploReg4.1 and GTEx database.

\section{Discussion}

To explore the contribution of genetic variation at 22q12 previously identified by our linkage analysis with vitiligo, we further performed imputation analysis for the expanded region of this locus in the discovery dataset and then replicated them in an independent cohort from Chinese Han population. This study identified that two novel genetic variants (rs730669 and rs4820338) at 22q11.2 were associated with vitiligo, and confirmed our previous reported variant (rs2051582) at 22q12.3 [12]. Several susceptible variants at 22q13.1 were also reported to be associated with vitiligo in the Caucasian population [6]. This study also showed the three independent associated signals at $22 \mathrm{q} 12$ for vitiligo.

The most strongly associated SNP rs730669 at the 22q11.2 locus, is located in a linkage disequilibrium (LD) block that includes multiple genes (Fig. 1), however, most of these genes function have remained largely unknown. SNP rs730669 at 22q11.2 is located in an intergenic region between ZDHHC8 and RTN4R. The ZDHHC8 contains 11 exons and encodes a palmitoyltransferase that share a conserved cysteine-rich signature catalytic domain (belonging to the 23-member family of enzymes). The genetic variants in ZDHHC8 have been reported to be associated with schizophrenia [18, 19], epilepsy [20] and total 
anomalous pulmonary venous connection [21]. The eQTL data shows that SNP rs730669 is associated with significant effect on the expression level of ZDHHC8 in cultured fibroblasts cells. Fibroblasts might affect melanocyte or epidermal pigmentation functionality by secreting skin aging-associated proteins from fibroblasts which favoring their loss and progression of vitiligo [22, 23]. It is well known that catecholamines (dopamine) acts as neurotransmitter which plays important role in pathogenesis of vitiligo [24]. The dopamine pathway probably affects directly melanogenesis or by the melanocortin pathway. ZDHHC8 can interact with the D2 dopamine receptor (D2R), which might influence the status of palmitoylation D2R [25]. The differentiation of mRNA expression for D2R gene is observed in skin for patient with vitiligo [26]. These indicate that ZDHHC8 might participate in the pathogenetic mechanisms for vitiligo by the above biological pathway.

For this locus, another gene RTN4R (also known as the neurite outgrowth inhibitor 66 (NgR)), contains 2 exons and encodes a glycosylphosphatidylinositol (GPI)-linked protein which plays an important role in the inhibition of myelin-mediated axonal growth by interacting with NgR [27]. The genetic variants at RTN4R have been reported to be associated with the anterior limb of the internal capsule and the psychosis with 22q11.2 deletion syndrome [28, 29]. Some studies also show that the differentiated expression of $\mathrm{NgR}$ on multiple immunological cells (monocytes, dendritic cells, T/B cells) influence the subsequent regulation of above cells adhesion or stimulation, which acts an important role in the pathogenesis for neuroinflammatory diseases such as multiple sclerosis $[30,31]$. Together, These further emphasize that neural-inflammatory mediators are implicated in vitiligo pathogenesis [32].

The associated SNP rs4820338 at 22q11.2 is located in an LD block that only contains VPREB1 (Fig. 1). VPREB1 contains 2 exons and encodes a protein which belongs to the immunoglobulin superfamily. It is expressed selectively at the early stages of immune $B$ cell development and to regulate the level of Ig gene rearrangements in the immune B cell differentiation. These show that transcriptional and metabolic pre-B cell receptor-mediated ingredients acts as important roles in pathogenesis for autoimmune diseases [33]. The deletion of VPREB1 has been reported to be associated with chronic autoimmune arthritis [34] and rheumatoid arthritis [35], and acute lymphoblastic leukemia [36, 37]. The lymphoid immune surveillance participates in vitiligo lesions and results in the lesion extension by triggering antigen-specific $T$ and B cell responses, which supports the involvement of immune response in disease development [38]. It is well known that the biological function of melanin-concentrating hormone receptor 1 (McHR1) has associated with the B-cell autoantigen located on the membrane of melanocytes by blocking the response of the receptor to $\mathrm{McH}$ [39]. Vitiligo has been reported to react against multiple epitopes on McHR1 [40, 41]. Therefore, it is speculated that the abnormal encoded proteins by VPREB1 might involve a variety of immunobiological pathways by the interaction between McHR1 and pre-B cell receptor-mediated ingredients, which further indicates that genetic and immune factors play an important role in the pathogenesis of vitiligo. Notably, early vitiligo onset is specifically associated with SNP rs4820338, which might contribute substantially to the heritability difference between the early-onset and late-onset subgroups.

This study identifies two novel independent variants rs730669 (ZDHHC8/RTN4R) and rs4820338 (VPREB1) at 22q11.2 that contributes to vitiligo susceptibility, which further emphasizes that the related- neuroimmunology genes play an important roles in the pathogenetic mechanisms for disease. The current findings provide an indirection for functional studies of candidate gene for this locus in future. It is still necessary to identify the causal gene(s) by the targeted sequencing and functional studies.

\section{Declarations}

Conflict of interest statement: All authors have no conflicts of interest to declare.

Funding: This current study was funded by the general program of the National Natural Science Foundation of China (No.81402591 and No.81972926).

Author contribution: Fengli Xiao and Xianfa Tang designed research; Hui Cheng, Lu Cheng and Bo Liang were responsible for sample selection and genotyping; Mengyun Chen and Xiaodong Zheng undertook data processing, statistical analysis and bioinformatics investigations; Xianfa Tang wrote the paper.

Ethics approval: This study was approved by the Institutional Ethical Committee of Anhui Medical University.

Consent to Participate (Ethics): Respect for participants and Informed consent to participate in this research.

Consent to Publish (Ethics): All authors agree to publication in this Journal and it is not under consideration for publication elsewhere.

Acknowledgements Thanks all individuals in this research.

\section{References}

1. D.H. Nunes, L.M. Esser, Vitiligo epidemiological profile and the association with thyroid disease, An Bras Dermatol 86 (2011) $241-248$.

2. K. Ezzedine, H.W. Lim, T. Suzuki, I. Katayama, I. Hamzavi, C.C. Lan, B.K. Goh, T. Anbar, C. Silva de Castro, A.Y. Lee, D. Parsad, N. van Geel, I.C. Le Poole, N. Oiso, L. Benzekri, R. Spritz, Y. Gauthier, S.K. Hann, M. Picardo, A. Taieb, Revised classification/nomenclature of vitiligo and related issues: the Vitiligo Global Issues Consensus Conference, Pigment Cell Melanoma Res 25 (2012) E1-13.

3. X.J. Zhang, J.J. Chen, J.B. Liu, The genetic concept of vitiligo, J Dermatol Sci 39 (2005) 137-146.

4. J.J. Chen, W. Huang, J.P. Gui, S. Yang, F.S. Zhou, Q.G. Xiong, H.B. Wu, Y. Cui, M. Gao, W. Li, J.X. Li, K.L. Yan, W.T. Yuan, S.J. Xu, J.J. Liu, X.J. Zhang, A novel linkage to generalized vitiligo on 4q13-q21 identified in a genomewide linkage analysis of Chinese families, Am J Hum Genet 76 (2005) $1057-1065$.

5. Y. Liang, S. Yang, Y. Zhou, J. Gui, Y. Ren, J. Chen, X. Fan, L. Sun, F. Xiao, M. Gao, W. Du, Q. Fang, S. Xu, W. Huang, X. Zhang, Evidence for two susceptibility loci on chromosomes 22q12 and 6p21-p22 in Chinese generalized vitiligo families, J Invest Dermatol 127 (2007) $2552-2557$. 
6. Y. Jin, S.A. Birlea, P.R. Fain, K. Gowan, S.L. Riccardi, P.J. Holland, C.M. Mailloux, A.J. Sufit, S.M. Hutton, A. Amadi-Myers, D.C. Bennett, M.R. Wallace, W.T. McCormack, E.H. Kemp, D.J. Gawkrodger, A.P. Weetman, M. Picardo, G. Leone, A. Taieb, T. Jouary, K. Ezzedine, N. van Geel, J. Lambert, A. Overbeck, R.A. Spritz, Variant of TYR and autoimmunity susceptibility loci in generalized vitiligo, N Engl J Med 362 (2010) 1686-1697.

7. Y. Jin, S.A. Birlea, P.R. Fain, C.M. Mailloux, S.L. Riccardi, K. Gowan, P.J. Holland, D.C. Bennett, M.R. Wallace, W.T. McCormack, E.H. Kemp, D.J. Gawkrodger, A.P. Weetman, M. Picardo, G. Leone, A. Taieb, T. Jouary, K. Ezzedine, N. van Geel, J. Lambert, A. Overbeck, R.A. Spritz, Common variants in FOXP1 are associated with generalized vitiligo, Nat Genet 42 (2010) 576-578.

8. Y. Jin, S.A. Birlea, P.R. Fain, T.M. Ferrara, S. Ben, S.L. Riccardi, J.B. Cole, K. Gowan, P.J. Holland, D.C. Bennett, R.M. Luiten, A. Wolkerstorfer, J.P. van der Veen, A. Hartmann, S. Eichner, G. Schuler, N. van Geel, J. Lambert, E.H. Kemp, D.J. Gawkrodger, A.P. Weetman, A. Taieb, T. Jouary, K. Ezzedine, M.R. Wallace, W.T. McCormack, M. Picardo, G. Leone, A. Overbeck, N.B. Silverberg, R.A. Spritz, Genome-wide association analyses identify 13 new susceptibility loci for generalized vitiligo, Nat Genet 44 (2012) 676-680.

9. Y. Jin, G. Andersen, D. Yorgov, T.M. Ferrara, S. Ben, K.M. Brownson, P.J. Holland, S.A. Birlea, J. Siebert, A. Hartmann, A. Lienert, N. van Geel, J. Lambert, R.M. Luiten, A. Wolkerstorfer, J.P. Wietze van der Veen, D.C. Bennett, A. Taieb, K. Ezzedine, E.H. Kemp, D.J. Gawkrodger, A.P. Weetman, S. Koks, Genome-wide association studies of autoimmune vitiligo identify 23 new risk loci and highlight key pathways and regulatory variants, 48 (2016) $1418-1424$.

10. S. Ben, Y. Jin, S.A. Santorico, R.A. Spritz, Genome-Wide Association of PVT1 with Vitiligo, J Invest Dermatol 138 (2018) 1884-1886.

11. C. Quan, Y.Q. Ren, L.H. Xiang, L.D. Sun, A.E. Xu, X.H. Gao, H.D. Chen, X.M. Pu, R.N. Wu, C.Z. Liang, J.B. Li, T.W. Gao, J.Z. Zhang, X.L. Wang, J. Wang, R.Y. Yang, L. Liang, J.B. Yu, X.B. Zuo, S.Q. Zhang, S.M. Zhang, G. Chen, X.D. Zheng, P. Li, J. Zhu, Y.W. Li, X.D. Wei, W.S. Hong, Y. Ye, Y. Zhang, W.S. Wu, H. Cheng, P.L. Dong, D.Y. Hu, Y. Li, M. Li, X. Zhang, H.Y. Tang, X.F. Tang, S.X. Xu, S.M. He, Y.M. Lv, M. Shen, H.Q. Jiang, Y. Wang, K. Li, X.J. Kang, Y.Q. Liu, L. Sun, Z.F. Liu, S.Q. Xie, C.Y. Zhu, Q. Xu, J.P. Gao, W.L. Hu, C. Ni, T.M. Pan, Y. Li, S. Yao, C.F. He, Y.S. Liu, Z.Y. Yu, X.Y. Yin, F.Y. Zhang, S. Yang, Y. Zhou, X.J. Zhang, Genome-wide association study for vitiligo identifies susceptibility loci at 6q27 and the MHC, Nat Genet 42 (2010) 614-618.

12. X.F. Tang, Z. Zhang, D.Y. Hu, A.E. Xu, H.S. Zhou, L.D. Sun, M. Gao, T.W. Gao, X.H. Gao, H.D. Chen, H.F. Xie, C.X. Tu, F. Hao, R.N. Wu, F.R. Zhang, L. Liang, X.M. Pu, J.Z. Zhang, J.W. Han, G.P. Pan, J.Q. Wu, K. Li, M.W. Su, W.D. Du, W.J. Zhang, J.J. Liu, L.H. Xiang, S. Yang, Y.W. Zhou, X.J. Zhang, Association analyses identify three susceptibility Loci for vitiligo in the Chinese Han population, J Invest Dermatol 133 (2013) 403-410.

13. R.A. Spritz, G.H. Andersen, Genetics of Vitiligo, Dermatol Clin 35 (2017) 245-255.

14. A. Taieb, M. Picardo, The definition and assessment of vitiligo: a consensus report of the Vitiligo European Task Force, Pigment Cell Res 20 (2007) $27-35$.

15. G.R. Abecasis, A. Auton, L.D. Brooks, M.A. DePristo, R.M. Durbin, R.E. Handsaker, H.M. Kang, G.T. Marth, G.A. McVean, An integrated map of genetic variation from 1,092 human genomes, Nature 491 (2012) 56-65.

16. B.N. Howie, P. Donnelly, J. Marchini, A flexible and accurate genotype imputation method for the next generation of genome-wide association studies, PLoS Genet 5 (2009) e1000529.

17. S. Purcell, B. Neale, K. Todd-Brown, L. Thomas, M.A. Ferreira, D. Bender, J. Maller, P. Sklar, P.I. de Bakker, M.J. Daly, P.C. Sham, PLINK: a tool set for wholegenome association and population-based linkage analyses, Am J Hum Genet 81 (2007) 559-575.

18. V.K. Ota, A. Gadelha, I.B. Assunção, M.L. Santoro, D.M. Christofolini, F.T. Bellucco, A.F. Santos-Filho, G.L. Ottoni, D.R. Lara, J.J. Mari, M.I. Melaragno, M.A. Smith, R.A. Bressan, S.I. Belangero, A.P. Jackowski, ZDHHC8 gene may play a role in cortical volumes of patients with schizophrenia, Schizophr Res 145 (2013) 33-35.

19. M. Xu, D. St Clair, L. He, Testing for genetic association between the ZDHHC8 gene locus and susceptibility to schizophrenia: An integrated analysis of multiple datasets, Am J Med Genet B Neuropsychiatr Genet 153b (2010) 1266-1275.

20. Q. Yang, F. Zheng, Y. Hu, Y. Yang, Y. Li, G. Chen, W. Wang, M. He, R. Zhou, Y. Ma, D. Xu, X. Tian, X. Gao, Q. Wang, X. Wang, ZDHHC8 critically regulates seizure susceptibility in epilepsy, Cell Death Dis 9 (2018) 795.

21. X. Shi, T. Huang, J. Wang, Y. Liang, C. Gu, Y. Xu, J. Sun, Y. Lu, K. Sun, S. Chen, Y. Yu, Next-generation sequencing identifies novel genes with rare variants in total anomalous pulmonary venous connection, EBioMedicine 38 (2018) 217-227.

22. S. Rani, S. Bhardwaj, N. Srivastava, V.L. Sharma, D. Parsad, R. Kumar, Senescence in the lesional fibroblasts of non-segmental vitiligo patients, Arch Dermatol Res 309 (2017) 123-132.

23. D. Kovacs, E. Bastonini, M. Ottaviani, C. Cota, E. Migliano, M.L. Dell'Anna, M. Picardo, Vitiligo Skin: Exploring the Dermal Compartment, J Invest Dermatol 138 (2018) 394-404.

24. M.I. Kotb El-Sayed, A.A. Abd El-Ghany, R.R. Mohamed, Neural and Endocrinal Pathobiochemistry of Vitiligo: Comparative Study for a Hypothesized Mechanism, Front Endocrinol (Lausanne) 9 (2018) 197.

25. B. Ebersole, J. Petko, M. Woll, S. Murakami, K. Sokolina, V. Wong, I. Stagljar, B. Luscher, R. Levenson, Effect of C-Terminal S-Palmitoylation on D2 Dopamine Receptor Trafficking and Stability, PLoS One 10 (2015) e0140661.

26. E. Reimann, K. Kingo, M. Karelson, P. Reemann, U. Loite, M. Keermann, K. Abram, E. Vasar, H. Silm, S. Koks, Expression profile of genes associated with the dopamine pathway in vitiligo skin biopsies and blood sera, Dermatology 224 (2012) 168-176.

27. A.E. Fournier, T. GrandPre, S.M. Strittmatter, Identification of a receptor mediating Nogo-66 inhibition of axonal regeneration, Nature 409 (2001) $341-346$.

28. M.D. Perlstein, M.R. Chohan, I.L. Coman, K.M. Antshel, W.P. Fremont, M.H. Gnirke, Z. Kikinis, F.A. Middleton, P.D. Radoeva, M.E. Shenton, W.R. Kates, White matter abnormalities in 22q11.2 deletion syndrome: preliminary associations with the Nogo-66 receptor gene and symptoms of psychosis, Schizophr Res 152 (2014) 117-123.

29. C.A. Thompson, J. Karelis, F.A. Middleton, K. Gentile, I.L. Coman, P.D. Radoeva, R. Mehta, W.P. Fremont, K.M. Antshel, S.V. Faraone, W.R. Kates, Associations between neurodevelopmental genes, neuroanatomy, and ultra high risk symptoms of psychosis in 22q11.2 deletion syndrome, Am J Med Genet B Neuropsychiatr Genet 174 (2017) 295-314. 
30. M. Pool, M. Niino, I. Rambaldi, K. Robson, A. Bar-Or, A.E. Fournier, Myelin regulates immune cell adhesion and motility, Exp Neurol 217 (2009) $371-377$.

31. C.L. McDonald, K. Steinbach, F. Kern, R. Schweigreiter, R. Martin, C.E. Bandtlow, M. Reindl, Nogo receptor is involved in the adhesion of dendritic cells to myelin, J Neuroinflammation 8 (2011) 113.

32. R. Yu, Y. Huang, X. Zhang, Y. Zhou, Potential role of neurogenic inflammatory factors in the pathogenesis of vitiligo, J Cutan Med Surg 16 (2012) $230-244$.

33. M. Zouali, Transcriptional and metabolic pre-B cell receptor-mediated checkpoints: implications for autoimmune diseases, Mol Immunol 62 (2014) 315320.

34. P. Pelkonen, P. Lahdenne, R. Lantto, V. Honkanen, Chronic arthritis associated with chromosome deletion 22 111.2 syndrome, J Rheumatol 29 (2002) 26482650.

35. S.H. Yim, Y.J. Chung, E.H. Jin, S.C. Shim, J.Y. Kim, Y.S. Kim, H.J. Hu, S.H. Shin, H.O. Pae, M. Zouali, H.T. Chung, The potential role of VPREB1 gene copy number variation in susceptibility to rheumatoid arthritis, Mol Immunol 48 (2011) 1338-1343.

36. D.S. Mangum, J. Downie, C.C. Mason, M.S. Jahromi, D. Joshi, V. Rodic, M. Müschen, N. Meeker, N. Trede, J.K. Frazer, Y. Zhou, C. Cheng, S. Jeha, C.H. Pui, C.L. Willman, R.C. Harvey, S.P. Hunger, J.J. Yang, P. Barnette, C.G. Mullighan, R.R. Miles, J.D. Schiffman, VPREB1 deletions occur independent of lambda light chain rearrangement in childhood acute lymphoblastic leukemia, Leukemia 28 (2014) 216-220.

37. U. Fischer, M. Forster, A. Rinaldi, T. Risch, S. Sungalee, H.J. Warnatz, B. Bornhauser, M. Gombert, C. Kratsch, A.M. Stutz, M. Sultan, J. Tchinda, C.L. Worth, V. Amstislavskiy, N. Badarinarayan, A. Baruchel, T. Bartram, G. Basso, C. Canpolat, G. Cario, H. Cave, D. Dakaj, M. Delorenzi, M.P. Dobay, C. Eckert, E. Ellinghaus, S. Eugster, V. Frismantas, S. Ginzel, O.A. Haas, O. Heidenreich, G. Hemmrich-Stanisak, K. Hezaveh, J.I. Holl, S. Hornhardt, P. Husemann, P. Kachroo, C.P. Kratz, G. Te Kronnie, B. Marovca, F. Niggli, A.C. McHardy, A.V. Moorman, R. Panzer-Grumayer, B.S. Petersen, B. Raeder, M. Ralser, P. Rosenstiel, D. Schafer, M. Schrappe, S. Schreiber, M. Schutte, B. Stade, R. Thiele, N. von der Weid, A. Vora, M. Zaliova, L. Zhang, T. Zichner, M. Zimmermann, H. Lehrach, A. Borkhardt, J.P. Bourquin, A. Franke, J.O. Korbel, M. Stanulla, M.L. Yaspo, Genomics and drug profiling of fatal TCF3-HLF-positive acute lymphoblastic leukemia identifies recurrent mutation patterns and therapeutic options, Nat Genet 47 (2015) 1020-1029.

38. L. Raam, E. Kaleviste, M. Sunina, H. Vaher, M. Saare, E. Prans, M. Pihlap, K. Abram, M. Karelson, P. Peterson, A. Rebane, K. Kisand, K. Kingo, Lymphoid Stress Surveillance Response Contributes to Vitiligo Pathogenesis, Front Immunol 9 (2018) 2707.

39. E.H. Kemp, E.A. Waterman, B.E. Hawes, K. O'Neill, R.V. Gottumukkala, D.J. Gawkrodger, A.P. Weetman, P.F. Watson, The melanin-concentrating hormone receptor 1, a novel target of autoantibody responses in vitiligo, J Clin Invest 109 (2002) 923-930.

40. N.G. Gavalas, R.V. Gottumukkala, D.J. Gawkrodger, P.F. Watson, A.P. Weetman, E.H. Kemp, Mapping of melanin-concentrating hormone receptor 1 B cell epitopes predicts two major binding sites for vitiligo patient autoantibodies, Exp Dermatol 18 (2009) 454-463.

41. M. Zhou, C. Guan, F. Lin, W. Xu, L. Fu, W. Hong, Y. Wan, A. Xu, Immunodetection of the MCHR1 antibody in vitiligo patient sera, Int J Mol Med 27 (2011) 725-729.

\section{Tables}

Table 1 Summary information of vitiligo patients and controls

\begin{tabular}{|lllllll|}
\hline Analysis & Cases & \multicolumn{5}{c|}{ Controls } \\
\cline { 2 - 7 } & Sample Size & Mean Age (s.d.) & Male (\%)/Female (\%) & Sample Size & Mean Age (s.d.) & Male (\%)/Female (\%) \\
\hline GWAS & 1117 & $28.73( \pm 15.00)$ & $656(58.73) / 461(41.27)$ & 1701 & $35.90( \pm 14.81)$ & $928(54.56) / 773(45.44)$ \\
Replication & 2069 & $28.82( \pm 14.41)$ & $1082(52.30) / 987(47.70)$ & 1370 & $31.43( \pm 14.74)$ & $754(55.04) / 616(44.96)$ \\
\hline Total & 3186 & $28.79( \pm 14.60)$ & $1738(54.55) / 1448(45.45)$ & 3071 & $33.47( \pm 14.63)$ & $1682(54.77) / 1389(45.23)$ \\
\hline
\end{tabular}

GWAS, genome-wide association study.

Tables 2 Association evidence for 8 SNPs in the GWAS, the replication study, and the combined analysis. 


\begin{tabular}{|c|c|c|c|c|c|c|c|c|c|c|c|c|c|c|}
\hline \multirow[t]{4}{*}{ SNP } & \multirow[t]{4}{*}{ Chr_pos } & \multirow[t]{4}{*}{ Gene } & \multirow[t]{4}{*}{ MA } & \multicolumn{5}{|l|}{ GWAS } & \multicolumn{5}{|c|}{ Replication study } & \multirow{4}{*}{$\begin{array}{l}\text { Comb } \\
3186 \\
\text { OR } \\
(95 \% C\end{array}$} \\
\hline & & & & \multicolumn{5}{|c|}{1117 cases, 1701 controls } & \multicolumn{5}{|c|}{2069 cases, 1370 controls } & \\
\hline & & & & \multicolumn{2}{|l|}{ MAF } & \multirow{2}{*}{$\begin{array}{l}\text { OR } \\
(95 \% \mathrm{Cl})\end{array}$} & \multirow[t]{2}{*}{$P$} & \multirow{2}{*}{$\begin{array}{l}\text { Call } \\
\text { rate }\end{array}$} & \multicolumn{2}{|l|}{ MAF } & \multirow{2}{*}{$\begin{array}{l}\text { OR } \\
(95 \% \mathrm{Cl})\end{array}$} & \multirow[t]{2}{*}{$P$} & \multirow{2}{*}{$\begin{array}{l}\text { Call } \\
\text { rate }\end{array}$} & \\
\hline & & & & Case & Control & & & & Case & Control & & & & \\
\hline rs730669 & 20214431 & ZDHHC8/RTN4R & C & 0.32 & 0.37 & $\begin{array}{l}0.81 \\
(0.73- \\
0.91)\end{array}$ & $\begin{array}{l}2.99 \mathrm{E}- \\
04\end{array}$ & 1.00 & 0.32 & 0.36 & $\begin{array}{l}0.82 \\
(0.74- \\
0.91)\end{array}$ & $\begin{array}{l}1.34 \mathrm{E}- \\
04\end{array}$ & 0.99 & $\begin{array}{l}0.81 \\
(0.75- \\
0.87)\end{array}$ \\
\hline rs5750483 & 22080038 & IGLV8-61 & A & 0.23 & 0.27 & $\begin{array}{l}0.82 \\
(0.73- \\
0.93)\end{array}$ & $\begin{array}{l}1.94 \mathrm{E}- \\
03\end{array}$ & 1.00 & 0.25 & 0.25 & $\begin{array}{l}0.96 \\
(0.86- \\
1.08)\end{array}$ & $\begin{array}{l}5.23 \mathrm{E}- \\
01\end{array}$ & 0.95 & $\begin{array}{l}0.89 \\
(0.82- \\
0.97)\end{array}$ \\
\hline rs4820338 & 22166665 & VPREB1 & C & 0.44 & 0.48 & $\begin{array}{l}0.83 \\
(0.75- \\
0.93)\end{array}$ & $\begin{array}{l}9.18 \mathrm{E}- \\
04\end{array}$ & 0.99 & 0.44 & 0.48 & $\begin{array}{l}0.88 \\
(0.80- \\
0.97)\end{array}$ & $\begin{array}{l}7.28 \mathrm{E}- \\
03\end{array}$ & 0.99 & $\begin{array}{l}0.86 \\
(0.80- \\
0.92)\end{array}$ \\
\hline rs490362 & 27335509 & LOC102724900 & $\mathrm{C}$ & 0.2 & 0.17 & $\begin{array}{l}1.27 \\
(1.11- \\
1.46)\end{array}$ & $\begin{array}{l}6.13 \mathrm{E}- \\
04\end{array}$ & 1.00 & 0.18 & 0.18 & $\begin{array}{l}1.03 \\
(0.91- \\
1.17)\end{array}$ & $\begin{array}{l}6.35 \mathrm{E}- \\
01\end{array}$ & 0.99 & $\begin{array}{l}1.13 \\
(1.03- \\
1.24)\end{array}$ \\
\hline rs133937 & 32999866 & SYN3 & $\mathrm{C}$ & 0.21 & 0.25 & $\begin{array}{l}0.83 \\
(0.73- \\
0.95)\end{array}$ & $\begin{array}{l}5.03 \mathrm{E}- \\
03\end{array}$ & 1.00 & 0.24 & 0.25 & $\begin{array}{l}0.96 \\
(0.86- \\
1.08)\end{array}$ & $\begin{array}{l}4.91 \mathrm{E}- \\
01\end{array}$ & 0.99 & $\begin{array}{l}0.92 \\
(0.85- \\
1.00)\end{array}$ \\
\hline rs2051582 & 37162316 & $I L 2 R B$ & A & 0.17 & 0.14 & $\begin{array}{l}1.24 \\
(1.07- \\
1.45)\end{array}$ & $\begin{array}{l}4.26 \mathrm{E}- \\
03\end{array}$ & 1.00 & 0.17 & 0.14 & $\begin{array}{l}1.27 \\
(1.11- \\
1.45)\end{array}$ & $\begin{array}{l}4.54 \mathrm{E}- \\
04\end{array}$ & 0.99 & $\begin{array}{l}1.27 \\
(1.15- \\
1.40)\end{array}$ \\
\hline rs5756587 & 37282163 & CYTH4 & $\mathrm{T}$ & 0.15 & 0.18 & $\begin{array}{l}0.79 \\
(0.68- \\
0.91)\end{array}$ & $\begin{array}{l}1.46 \mathrm{E}- \\
03\end{array}$ & 1.00 & 0.17 & 0.16 & $\begin{array}{l}1.04 \\
(0.91- \\
1.19)\end{array}$ & $\begin{array}{l}5.50 \mathrm{E}- \\
01\end{array}$ & 0.97 & $\begin{array}{l}0.92 \\
(0.84- \\
1.01)\end{array}$ \\
\hline rs4820287 & 37394071 & ELFN2 & C & 0.24 & 0.28 & $\begin{array}{l}0.81 \\
(0.71- \\
0.91)\end{array}$ & $\begin{array}{l}6.65 \mathrm{E}- \\
04\end{array}$ & 0.99 & 0.26 & 0.26 & $\begin{array}{l}1.04 \\
(0.93- \\
1.16)\end{array}$ & $\begin{array}{l}5.40 \mathrm{E}- \\
01\end{array}$ & 0.99 & $\begin{array}{l}0.92 \\
(0.85- \\
1.00)\end{array}$ \\
\hline
\end{tabular}

GWAS, genome-wide association study, SNP, single-nucleotide polymorphism, Chr_pos, chromosome position, MA, minor allele, MAF, minor allele frequency, $\mathrm{OR}$, odds ratio, $\mathrm{Cl}$, confidence interval.

Tables 3 The results of conditional regression analysis.

\begin{tabular}{|c|c|c|c|c|c|}
\hline SNP & $r^{2}$ & $D^{\prime}$ & Condition on SNP & $P$ & OR \\
\hline rs730669 & \multirow[t]{2}{*}{ 4.51E-04 } & \multirow[t]{2}{*}{ 3.17E-02 } & \multirow[t]{2}{*}{ rs2051582 } & 4.15E-08 & 0.81 \\
\hline rs4820338 & & & & $9.13 \mathrm{E}-06$ & 0.85 \\
\hline rs2051582 & \multirow[t]{2}{*}{$1.13 \mathrm{E}-05$} & \multirow[t]{2}{*}{$7.25 \mathrm{E}-03$} & \multirow[t]{2}{*}{ rs730669 } & 2.17E-06 & 1.27 \\
\hline rs4820338 & & & & $5.12 \mathrm{E}-06$ & 0.84 \\
\hline rs730669 & \multirow[t]{2}{*}{ 8.28E-05 } & \multirow[t]{2}{*}{ 2.93E-02 } & \multirow[t]{2}{*}{ rs4820338 } & 7.87E-09 & 0.80 \\
\hline rs2051582 & & & & 3.07E-06 & 1.26 \\
\hline
\end{tabular}

SNP, single-nucleotide polymorphism, OR, odds ratio.

Tables 4 Distribution of genotypes and alleles for SNP rs4820338 in subgroups. 


\begin{tabular}{|c|c|c|c|c|c|c|c|c|}
\hline \multirow[t]{2}{*}{ Subphenotypes } & \multicolumn{4}{|c|}{ Genotype frequency (\%) } & \multicolumn{4}{|c|}{ Allele frequency (\%) } \\
\hline & $\mathrm{CC}$ & CG & GG & $P^{a}$ & C & G & $P^{b}$ & $\mathrm{OR}(95 \% \mathrm{Cl})$ \\
\hline \multicolumn{9}{|l|}{ Age at onset } \\
\hline Early onset $<=20$ years $(n=1703)$ & 291(17.09) & $873(51.26)$ & $539(31.65)$ & \multirow[t]{2}{*}{$2.30 \mathrm{E}-02$} & 1455(42.72) & 1951(57.28) & \multirow[t]{2}{*}{ 7.78E-03 } & \multirow[t]{2}{*}{$0.87(0.79-0.97)$} \\
\hline Late onset $>20$ years $(n=1447)$ & 286(19.77) & $761(52.59)$ & $400(27.64)$ & & 1333(46.06) & 1561(53.94) & & \\
\hline \multicolumn{9}{|l|}{ Gender } \\
\hline Male(n=1714) & $320(18.67)$ & $884(51.58)$ & $510(29.75)$ & \multirow[t]{2}{*}{0.85} & $1524(44.46)$ & 1904(55.54) & \multirow[t]{2}{*}{0.72} & \multirow[t]{2}{*}{$1.02(0.92-1.13)$} \\
\hline Female $(n=1436)$ & $257(17.90)$ & $750(52.23)$ & $429(29.87)$ & & $1264(44.01)$ & 1608(55.99) & & \\
\hline \multicolumn{9}{|l|}{ Family history } \\
\hline Positive(n=414) & $89(21.50)$ & $213(51.45)$ & $112(27.05)$ & \multirow[t]{2}{*}{0.15} & $391(47.22)$ & $437(52.78)$ & \multirow[t]{2}{*}{0.07} & \multirow[t]{2}{*}{$1.15(0.99-1.33)$} \\
\hline Negative(2736) & $488(17.84)$ & 1421(51.94) & $827(30.22)$ & & 2397(43.80) & $3075(56.20)$ & & \\
\hline \multicolumn{9}{|l|}{ Clinical classification } \\
\hline Non segmental(n=2297) & $439(19.11)$ & 1173(51.07) & $685(29.82)$ & \multirow[t]{2}{*}{0.14} & 2051(44.65) & 2543(55.35) & \multirow[t]{2}{*}{0.31} & \multirow[t]{2}{*}{$1.06(0.95-1.19)$} \\
\hline Segmental(n=853) & 138(16.18) & $461(54.04)$ & $254(29.78)$ & & $737(43.20)$ & $969(56.80)$ & & \\
\hline \multicolumn{9}{|l|}{ Autoimmune disease involvement } \\
\hline Positive(n=92) & $20(21.74)$ & $49(53.26)$ & $23(25.00)$ & \multirow[t]{2}{*}{0.50} & $89(48.37)$ & $95(51.63)$ & \multirow[t]{2}{*}{0.25} & \multirow[t]{2}{*}{$1.19(0.88-1.59)$} \\
\hline Negative(n=3058) & $557(18.21)$ & 1585(51.83) & $916(29.96)$ & & 2699(44.13) & $3417(55.87)$ & & \\
\hline \multicolumn{9}{|l|}{ Koebner phenomenon } \\
\hline Positive $(\mathrm{n}=236)$ & $51(21.61)$ & $121(51.27)$ & $64(27.12)$ & \multirow[t]{2}{*}{0.34} & $223(47.25)$ & $249(52.75)$ & \multirow[t]{2}{*}{0.17} & \multirow[t]{2}{*}{ 1.14(0.94-1.38) } \\
\hline Negative(n=2914) & $526(18.05)$ & 1513(51.92) & $875(30.03)$ & & 2565(44.01) & $3263(55.99)$ & & \\
\hline
\end{tabular}

$\mathrm{OR}$, odds ratio, $\mathrm{Cl}$, confidence interval.

a For genotype using a $2 \times 3$ contingency table. ${ }^{b}$ For allele using a $2 \times 2$ contingency table.

\section{Figures}



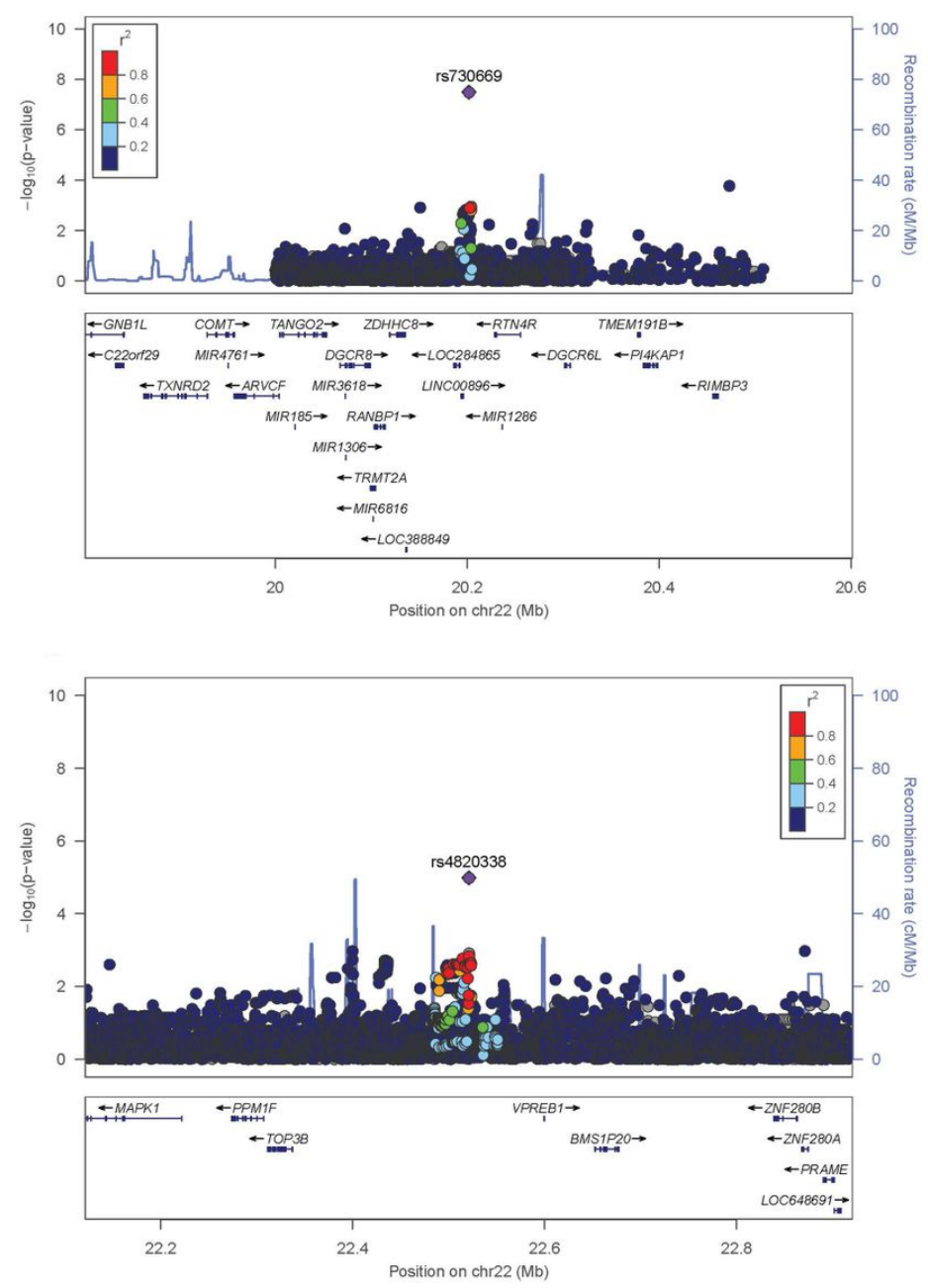

\section{Figure 1}

Regional association plot for the associated SNPs rs730669 and rs4820338 at 22q11.2 region. SNP is plotted by chromosomal position (GRCh38/hg19, $\mathrm{x}$ axis) and association with vitiligo from current study (-log10P-value, y axis). Estimated recombination rates (based on the combined CHB and JPT samples from the HapMap project) were plotted in light blue. Genes are indicated in the lower panel of the plot. 